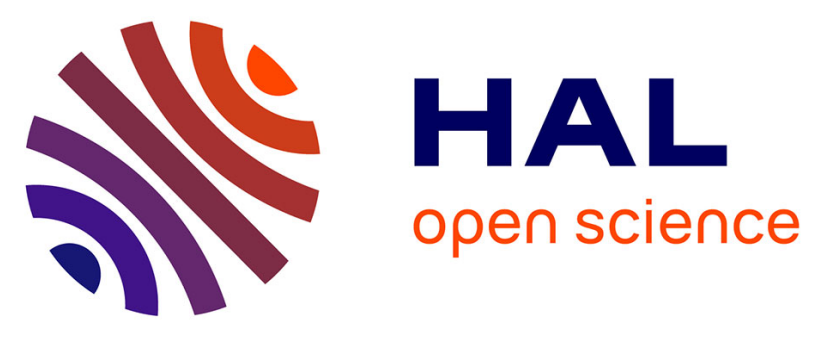

\title{
Handling Geometric Features in Nanoscale Characterization of Charge Injection and Transport in thin Dielectric Films
}

Christina Villeneuve-Faure, Kremena Makasheva, Laurent Boudou, G.

Teyssedre

\section{To cite this version:}

Christina Villeneuve-Faure, Kremena Makasheva, Laurent Boudou, G. Teyssedre. Handling Geometric Features in Nanoscale Characterization of Charge Injection and Transport in thin Dielectric Films. 2018 IEEE 2nd International Conference on Dielectrics (ICD), Jul 2018, Budapest, Hungary. pp.1-4, 10.1109/ICD.2018.8468409 . hal-02324374

\section{HAL Id: hal-02324374 \\ https://hal.science/hal-02324374}

Submitted on 1 Nov 2019

HAL is a multi-disciplinary open access archive for the deposit and dissemination of scientific research documents, whether they are published or not. The documents may come from teaching and research institutions in France or abroad, or from public or private research centers.
L'archive ouverte pluridisciplinaire HAL, est destinée au dépôt et à la diffusion de documents scientifiques de niveau recherche, publiés ou non, émanant des établissements d'enseignement et de recherche français ou étrangers, des laboratoires publics ou privés. 


\title{
Handling geometric features in nanoscale characterization of charge injection and transport in thin dielectric films
}

\author{
C. Villeneuve-Faure*, K. Makasheva, L. Boudou, G. Teyssedre \\ LAPLACE, Université de Toulouse, \\ CNRS, INPT, UPS, Bat 3R3, 118 route de Narbonne, F-31062 Toulouse Cedex 9, France \\ ${ }^{*}$ Christina.villeneuve@laplace.univ-tlse.fr
}

\begin{abstract}
Due to miniaturization and attractiveness of nanosized and/or nanostructured dielectric layers, characterization at the local scale of charge injection and transport phenomena comes to the fore. To that end the electric modes derived from Atomic Force Microscopy (AFM) are more and more frequently used. In this study, the influence of AFM tip-plane system configuration on the electric field distribution is investigated for homogeneous and heterogeneous (nanostructured) thin dielectric layers. The experimental and computing results reveal that the radial component of the electric field conveys the charge lateral spreading whereas the axial component of the electric field governs the amount of injected charges. The electric field distribution is slightly influenced by the heterogeneity of the material. Moreover, the interpretation of the current measurements requires consideration of the entire electric field distribution and not only the computed field at the contact point.
\end{abstract}

Keywords-thin layer, dielectric, KPFM, C-AFM, electric field

\section{INTRODUCTION}

All dielectric materials present common feature to accumulate charges under electrical stress. This phenomenon appears the main failure mechanism for a large number of applications [1-2]. Consequently, charges injection and transport mechanisms need to be finely understood and well controlled to improve reliability. Due to the nanomaterials attractiveness for electronic and energy applications [3] and the scaling down of the dimension of electronic devices [4], these mechanisms need to be characterized at local scale. To that end electrical modes, derived from Atomic Force Microscopy (AFM), as Kelvin Probe Force Microscopy (KPFM), Electrostatic Force Microscopy (EFM) and Conductive AFM (C-AFM) are more and more frequently used for characterization of thin dielectric layers [5-7]. However, the results provided by such techniques rely strongly on the tipplane geometry involved in either charge injection or measurement configurations. Particularly, the extraction of the physical parameters (charge density, injection barrier, conduction...) from the experimental results is based on accurate modelling of electrostatic interaction between the tip and the dielectric layer under study.
The aim of this work is to evaluate the impact of AFM tipplane geometry on the charge injection and transport. Two kinds of dielectric materials were investigated: homogeneous amorphous silicon oxynitride $a-\mathrm{SiO}_{\mathrm{x}} \mathrm{N}_{\mathrm{y}}$ thin layers with composition close to $\mathrm{SiO}_{2}$ and heterogeneous layers composed of silver nanoparticles (AgNPs) embedded in organosilicon SiOC:H matrix. For each kind of samples, the electric field in injection configuration was computed and exploited to interpret the experimental results. Afterwards, current measurements by C-AFM were performed to complete the study.

\section{EXPERIMENTS AND MODDELLING}

\section{A. Experiments}

Thin $\mathrm{SiO}_{\mathrm{x}} \mathrm{N}_{\mathrm{y}}$ dielectric layers of different thicknesses $(31.1 \pm 0.2,50.0 \pm 0.3,68.1 \pm 0.3$ and $129.9 \pm 0.9 \mathrm{~nm})$ were elaborated by Pulsed Plasma Enhanced Chemical Vapor Deposition (PPECVD) on gold electrodes. The plasma process details are presented elsewhere [8]. The $\mathrm{SiO}_{\mathrm{x}} \mathrm{N}_{\mathrm{y}}$ thicknesses were obtained by spectroscopic ellipsometry measurements after applying Forouhi-Bloomer dispersion law for the spectra interpretation [8].

The SiOC:H layers with embedded AgNPs were deposited on thermal $\mathrm{SiO}_{2}$ layers $(522.6 \pm 2.6 \mathrm{~nm})$ grown on intrinsic Sisubstrates by using a hybrid Physical Vapor Deposition (PVD)/PECVD process [9]. These samples present a single layer of AgNPs embedded in the $\mathrm{SiOC}: \mathrm{H}$ matrix at $24.0 \mathrm{~nm}$ from the sample surface. The AgNPs exhibit a prolate spheroid shape with a mean size of $19.6 \pm 7.8 \mathrm{~nm}$ and are spaced by $10 \pm 5.0 \mathrm{~nm}[9]$.

AFM measurements were performed using a Bruker Multimode 8 apparatus under controlled environment. Charges were injected in contact (contact force of $90 \mathrm{nN}$ ) using a silicon AFM tip with $\mathrm{Pt} / \mathrm{Ir}$ coating materials (curvature radius $\mathrm{R}_{\mathrm{c}}=25 \mathrm{~nm}$ and cantilever stiffness $\mathrm{k}=2.4 \mathrm{~N} / \mathrm{m}$ ) and applying positive DC bias $(10-40 \mathrm{~V})$ to the AFM tip during $1 \mathrm{~min}$, the sample backside being grounded. The resulting surface potential modification is probed in the Amplitude Modulation KPFM (AM-KPFM) with $10 \mathrm{~nm}$-lift.

Current measurements were performed in C-AFM mode (low noise amplifier within the $20 \mathrm{pA}$-range, using a diamond coated $\mathrm{Si}$ tip $(\mathrm{Rc}=125 \mathrm{~nm}$ and $\mathrm{k}=2 \mathrm{~N} / \mathrm{m})$. Bias voltages 
between $1 \mathrm{~V}$ and $20 \mathrm{~V}$ were applied on the Au-electrode and the current was acquired during $60 \mathrm{~s}$ for each bias level.

\section{B. Electric field and current density computing}

Electric field and electrical current, in injection configuration, were computed using a 2D-axisymmetric finiteelement model (FEM) developed on COMSOL Multiphysics. The AFM tip was modelled by a truncated cone of $10 \mu \mathrm{m}-$ height with $14^{\circ}$ aperture angle ending with a semi-spherical apex $\left(R_{c}=25 \mathrm{~nm}\right.$ or $\left.R_{c}=125 \mathrm{~nm}\right)$. The tip was supposed to be surrounded by an air box (dimension large enough to avoid edge effects) and put in contact with the dielectric layers of different thicknesses. The relative dielectric permittivity, of the $\mathrm{SiO}_{\mathrm{x}} \mathrm{N}_{\mathrm{y}}$ dielectric layer, was taken equal to 3.9 [8]. A refined mesh was optimized close to the contact point to improve calculation accuracy.

The Poisson's equation was solved in air and in the dielectric layer to determine the electric field $\mathbf{E}$ and the potential V. Without charges, it is of the form:

$$
\begin{gathered}
\operatorname{div}(\mathbf{E})=0 \\
\mathbf{E}=-\operatorname{grad}(\mathrm{V})
\end{gathered}
$$

The current density $\mathbf{J}$ is determined under the assumption that the conduction is the main mechanism by using the following equation:

$$
\mathbf{J}=\sigma \mathbf{E}
$$

where $\sigma$ is the dielectric layer conductivity taken equal to $4.54 \times 10^{-16} \mathrm{~S} / \mathrm{m}$, as measured for the $\mathrm{SiO}_{\mathrm{x}} \mathrm{N}_{\mathrm{y}}$ layer [8].

\section{INFLUENCE OF LOCAL ELECTRIC FIELD ON CHARGE INJECTION}

\section{A. Homogeneous dielectric layer}

The electric field was computed for $\mathrm{SiO}_{\mathrm{x}} \mathrm{N}_{\mathrm{y}}$ dielectric layers with different thicknesses using equations (1) and (2). Due to the tip-plane configuration the radial contribution of the electric field $E_{\mathrm{r}}$ (Fig. 1.a) in air and in the dielectric is quite significant and cannot be neglected compared to the axial contribution of the electric field $\mathrm{E}_{\mathrm{z}}$ (Fig. 1.b.). The $\mathrm{E}_{\mathrm{r}}$-field distribution at the dielectric/air interface $(z=0)$ is represented in Fig. 1.c. The maximum of the $\mathrm{E}_{\mathrm{r}}$ field is at finite distance $r_{\max }$ from the axis. Fig. 1.d presents the evolution of $E_{z}$ as a function of the in-depth position in the dielectric layer (along the vertical axis, $r=0$ ) for the same conditions. Close to the dielectric surface, the electric field is substantially enhanced compared to a plane-plane configuration $\left(2 \times 10^{8} \mathrm{~V} / \mathrm{m}\right)$. This effect increases with the dielectric thickness increase (Table I). Moreover it is straightened for dielectrics with higher relative dielectric permittivity.

TABLE I. COMPARISION OF RADIAL AND AXIAL ELECTRIC FIELD COMPONENTS AS FUNCTION OF $\mathrm{SIO}_{\mathrm{X}} \mathrm{N}_{\mathrm{Y}}$ THICKNESS.

\begin{tabular}{|c|c|c|c|c|}
\hline $\begin{array}{c}\mathbf{S i O}_{\mathbf{x}} \mathbf{N}_{\mathbf{y}} \\
\text { thickness }\end{array}$ & $\begin{array}{c}\text { Bias on } \\
\mathbf{A F M ~ t i p ~}^{\text {a }}\end{array}$ & $\begin{array}{c}\mathbf{E}_{\mathbf{r}}(\mathbf{m a x}) \\
\left(\mathbf{1 0}^{\mathbf{8}} \mathbf{V} / \mathbf{m}\right)\end{array}$ & $\begin{array}{c}\mathbf{E}_{\mathbf{z}}(\mathbf{m a x}) \\
\left(\mathbf{1 0}^{\mathbf{8}} \mathbf{V} / \mathbf{m}\right)\end{array}$ & $\begin{array}{c}\mathbf{E}_{\mathbf{z}}(\mathbf{m i n}) \\
\left(\mathbf{1 0}^{\mathbf{8}} \mathbf{V} / \mathbf{m}\right)\end{array}$ \\
\hline $5 \mathrm{~nm}$ & $1 \mathrm{~V}$ & 0.5 & 2.6 & 1.8 \\
\hline $10 \mathrm{~nm}$ & $2 \mathrm{~V}$ & 1.2 & 3.6 & 1.7 \\
\hline $50 \mathrm{~nm}$ & $10 \mathrm{~V}$ & 3.5 & 10.0 & 1.2 \\
\hline $100 \mathrm{~nm}$ & $20 \mathrm{~V}$ & 5.5 & 17.5 & 1.0 \\
\hline
\end{tabular}

${ }^{a}$ Applied bias such to provide an electric field of $2 \times 10^{8} \mathrm{~V} / \mathrm{m}$ in plane-plane configuration
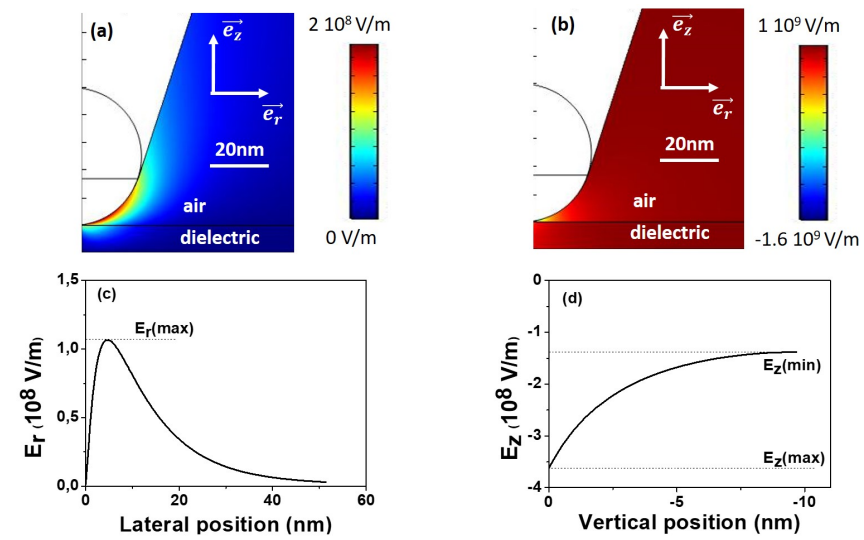

Fig. 1. Spatial distribution of the computed (a) radial Er and (b) axial Ez electric field for $2 \mathrm{~V}$ applied on AFM tip and $10 \mathrm{~nm}$-thick $\mathrm{SiO}_{\mathrm{x}} \mathrm{N}_{\mathrm{y}}$ film. (c) $\mathrm{E}_{\mathrm{r}}(\mathrm{z}=0)$ and $(\mathrm{d}) \mathrm{E}_{\mathrm{z}}(\mathrm{r}=0)$ cross section.

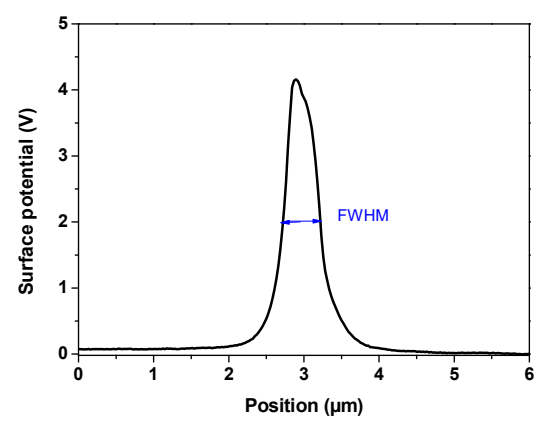

Fig. 2. Surface potential profile measured by KPFM after charge injection at $30 \mathrm{~V}$ during $1 \mathrm{~min}$ in $50 \mathrm{~nm}$-thick $\mathrm{SiO}_{\mathrm{x}} \mathrm{N}_{\mathrm{y}}$ layer.
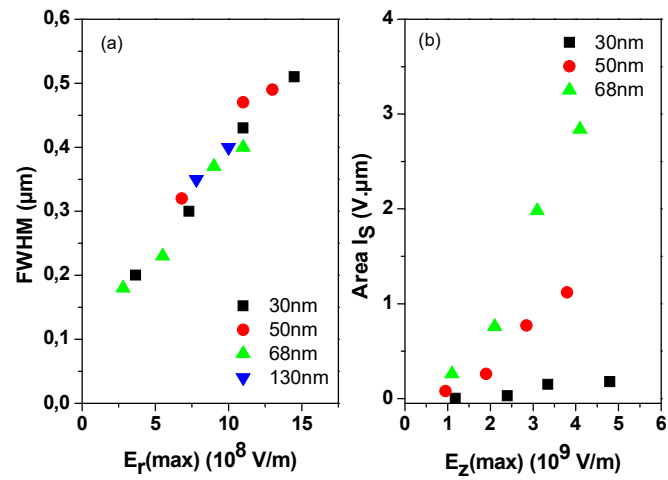

Fig. 3. Evolution of surface potential profile (a) FWHM and (b) area under peak as fonction of respectively radial $E_{\mathrm{r}}$ and axial $\mathrm{E}_{\mathrm{z}}$ electric field. Injection was done in $\mathrm{SiO}_{\mathrm{x}} \mathrm{N}_{\mathrm{y}}$ layers of different thicknesses during $1 \mathrm{~min}$.

Charge injection was performed under tip bias varying from $10 \mathrm{~V}$ to $40 \mathrm{~V}$ using steps of $10 \mathrm{~V}$, applied for $1 \mathrm{~min}$. The KPFM profiles were recorded immediately after voltage application, along a line crossing the injection point. The surface potential profile (Fig. 2) exhibits a bell-like shape representative of the amount of injected charges [10]. Two parameters, relevant for charge injection investigation could be extracted : (i) the peak full width at half maximum (FWHM) 
which reflects the lateral spreading of injected charges; and (ii) the area under the potential profile Is, which represents to a first approximation the quantity of stored charges in the dielectric layer [11].

As shown on Fig. 3.a, the FWHM of potential profile increases with the maximum of the radial component of the electric field whatever the dielectric thickness. Thus, the radial electric field influences charge spreading in the dielectric layer. Moreover, the area under the pic $\mathrm{I}_{\mathrm{s}}$ increases with the axial component of the electric field and the slope depends on the dielectric thickness. For a given dielectric thickness, this is consistent with the fact that axial electric field governs the amount of injected charges. This phenomenon was already observed investigating influence of AFM-tip metal coating on charge injection [10]. The confirmation here strengthens the statement on its effect.

\section{B. Heterogeneous dielectric layer}

The electric field was computed for SiOC:H layer with embedded AgNPs for different distances D between the nanoparticles plane and the dielectric surface by using equations (1) and (2). Fig. 4 represents the radial $E_{r}$ and axial $E_{z}$ electric field components when the top of AgNPs is located at $5 \mathrm{~nm}$ under the SiOC:H surface. The presence of metallic inclusions, i.e. the AgNPs, modifies the electric field distribution in the layer. As shown on Table II, the radial and axial electric field components are enhanced due to the AgNPs and the strengthening increases as the AgNPs approach the surface. The axial electric field remains unchanged in the dielectric part beneath the nanoparticles.

This model shows that the electric field strengthening is less pronounced when the nanoparticle permittivity decreases. Indeed, for nanoparticles with permittivity in the same range as the host matrix $\left(\varepsilon_{\mathrm{r}}=2-10\right)$, this effect is negligible.

Charge injection was performed under tip bias varying from $5 \mathrm{~V}$ to $25 \mathrm{~V}$ using $5 \mathrm{~V}$ steps applied for $1 \mathrm{~min}$. The KPFM profiles were recorded immediately after voltage application, along a line crossing the injection point. This profile exhibits the same bell-like shape as in Fig. 2. As the AgNPs are located $24.2 \mathrm{~nm}$ under the SiOC:H surface, it is considered that the axial and radial electric field components are not modified by their presence (cf. Table 2). As previously, the surface potential profile increases with the radial electric field (Fig. 5.a) but this increase is more important with embedded AgNPs. So, charge lateral spreading is favored due to AgNPs embedded in the matrix. The same trend is observed for the charge amount. Indeed, the area $\mathrm{I}_{\mathrm{s}}$ under the charge peak increases with the maximum of the axial component of the electric field and this increase is more important (by a factor of 8) in presence of AgNPs. Consequently, the embedded in the host matrix AgNPs modify the charge injection and transport in the dielectric layer even though they do not influence substantially the initial electric field at the surface.
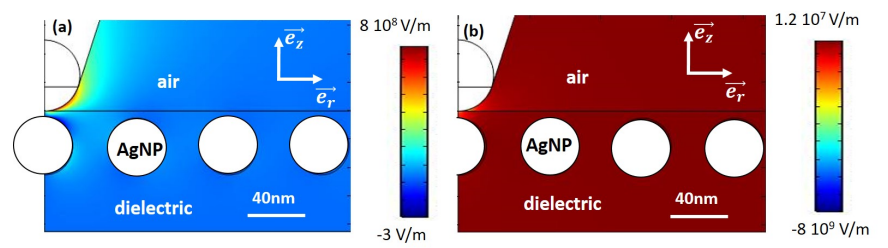

Fig. 4. Spatial distribution of the computed electric field: (a) radial contribution $\mathrm{E}_{\mathrm{r}}$ and (b) axial contribution $\mathrm{E}_{\mathrm{z}}$ for $10 \mathrm{~V}$ applied on $85 \mathrm{~nm}$-thick $\mathrm{SiO}_{2}$ layer with embedded AgNPs. Distance between the nanoparticles is $20 \mathrm{~nm}$ and distance from the surface is $5 \mathrm{~nm}$.
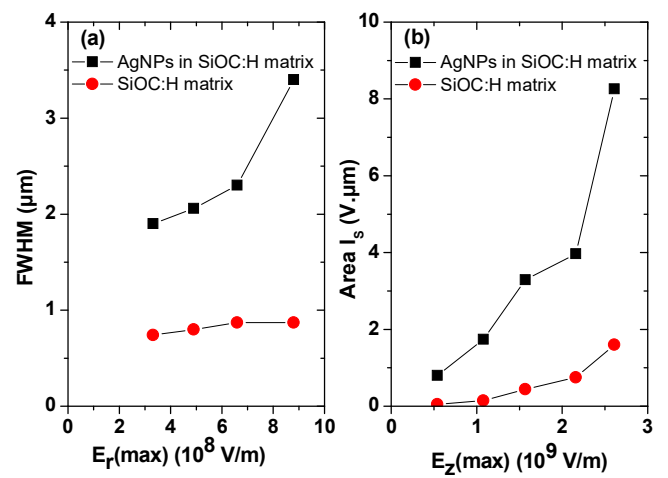

Fig. 5. Evolution of the surface potential: (a) FWHM as a fonction of the radial electric field $E_{\mathrm{r}}$ and (b) area $\mathrm{I}_{\mathrm{S}}$ under the charge peak as a fonction of the axial electric field $E_{z}$ for injection in $470 \mathrm{~nm}$-thick SiOC:H layer with and without embedded AgNPs located at $24.2 \mathrm{~nm}$ from the sample surface (injection time $1 \mathrm{~min}$ ).

TABLE II. COMPARISION OF THE RADIAL ER AND AXIAL EZ ELECTRIC FIELD COMPONENTS AS A FUNCTION OF THE DISTANCE D BETWEEN THE AGNPS AND THE SIOC:H SURFACE. RESULTS FOR 10V BIAS ON THE AFM TIP AND TOTAL DIELECTRIC LAYER THICKNESS OF 85NM.

\begin{tabular}{|c|c|c|c|}
\hline Distance D (nm) & $\begin{array}{c}\mathbf{E}_{\mathbf{r}}(\mathbf{m a x}) \\
\left(\mathbf{1 0}^{\mathbf{8}} \mathbf{V} / \mathbf{m}\right)\end{array}$ & $\begin{array}{c}\mathbf{E}_{\mathbf{z}} \mathbf{( m a x )} \\
\left.\mathbf{( 1 0}^{\mathbf{8}} \mathbf{V} / \mathbf{m}\right)\end{array}$ & $\begin{array}{c}\mathbf{E}_{\mathbf{z}}(\mathbf{m i n}) \\
\left.\mathbf{( 1 0}^{\mathbf{8}} \mathbf{V} / \mathbf{m}\right)\end{array}$ \\
\hline No AgNPs & 3.2 & 9.6 & 0.5 \\
\hline 5 & 4.4 & 17.5 & 0.5 \\
\hline 10 & 3.7 & 13.0 & 0.5 \\
\hline 25 & 3.2 & 10.0 & 0.5 \\
\hline 40 & 3.2 & 9.6 & 0.5 \\
\hline
\end{tabular}

\section{CurRent MEASUREMENT}

Current through dielectric layer was measured in charge injection condition (AFM tip in contact with dielectric surface). Fig. 6.a represents the current evolution measured by C-AFM as a function of the axial electric field at the contact point for tip-plane configuration (i.e. $\mathrm{E}_{\mathrm{z}}(\max )$ on Fig.1.d.).These results interpretation is not straightforward and three main issues can be identified.

The first one is related to electric field inhomogeneity. Indeed, classical laws for charge injection mechanisms (MottGurney, Schottky or Poole-Frenkel laws) imply homogeneous distribution of the electric field in dielectric layer, which is wrong in our configuration (see Fig.1). For example, O. Reid et al [12] demonstrate that using Mott-Gurney law to interpret CAFM measurement in a semiconductor layer implies electron/hole mobility determination three orders of magnitude 
higher than using macroscopic Metal-Semiconductor-Metal structures. This is mainly due to the wrong hypothesis about electric field and current density homogeneity. Indeed, as the conduction is the only mechanism, modelling based on FEM reveal strong current density localization in the volume close to the AFM tip (Fig. 6.b) and divergence of the field.

Moreover, as shown previously charges are injected and trapped in the dielectric layer. Consequently, injected charge distribution should be taken into account for the electric field modelling. The stored charges can significantly modify the electric field computed in the previous section. To reach this goal injected charge distribution should be extracted from KPFM measurements presented in III.A which is not yet possible. Consequently, the electric field heterogeneity and injected charge in all dielectric layers needs to be taken into account when modeling the C-AFM measurements.

The last issue concerns the determination of the physical contact between the AFM-tip and the dielectric surface which permits to determine the current density from C-AFM measurement. Concerning ultra-thin dielectric layers, three main approaches are used to determine the collection area: $(i)$ Contact area is computed using the Hertz approach, corresponding to the mechanical contact area [13]; (ii) Effective surface is determined fitting the current-voltage experimental curve. This surface depends on few parameters as tip work function, contact force or dielectric thickness and presents a broad range values from $10 \mathrm{~nm}^{2}$ to $100 \mathrm{~nm}^{2}$ [14]; (iii) Scanning Electron Microscopy observations on the AFM tip after measurements [15]. Additionally, surface roughness needs to be considered to evaluate the current collection area. Concerning the $\mathrm{SiO}_{\mathrm{x}} \mathrm{N}_{\mathrm{y}}$ sample surface roughness is small enough (arithmetic roughness equal to $1.2 \mathrm{~nm}$ over $1 \mu \mathrm{m} \times 1 \mu \mathrm{m}$ ) and do not influence the current collection.

\section{CONCLUSION}

In this work, the influence of tip-plane configuration, involved in AFM configuration measurements, on the electric field in thin dielectric layer is studied. Experimental and FEM results demonstrate that concerning the charge injection mechanism the radial electric field influences the charge lateral spreading whereas the axial electric field governs the amount of injected charges. Moreover, the nanostructured nature of the dielectric layer influences mainly the injection process. Concerning the C-AFM measurements, the macroscopic laws failed to interpret experimental results and new model needs to be developed to reproduce the real configuration (electric field heterogeneity distribution and influence of injected charge). Indeed, taking into account the electric field at the contact point is not enough to reproduce the real conditions and its distribution in the volume should be implemented in the model.

\section{REFERENCES}

[1] A. Witvrouw, H.A.C. Tilmans and I. De Wolf "Materials issues in the processing, the operation and the reliability of MEMS" Microelectronic Engineering, Vol. 76, pp. 245-257, 2007.
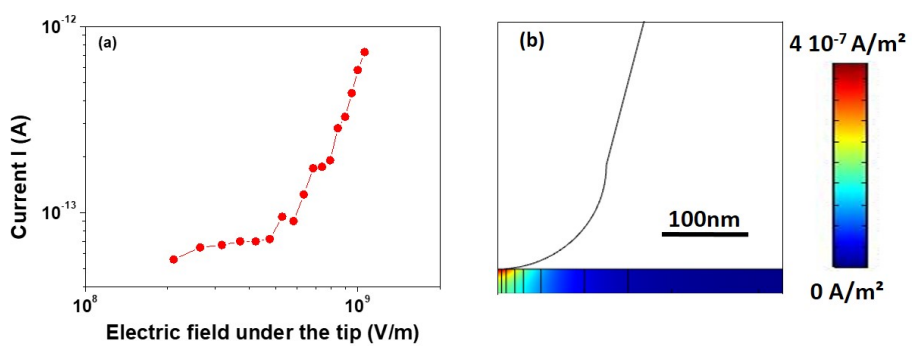

Fig. 6. Evolution of C-AFM current as a fonction of the axial electric field at the contact point $\mathrm{E}_{\mathrm{z}}(\mathrm{r}=0$; $\mathrm{z}=0)$, (b) Current density modulus distribution in $30 \mathrm{~nm}$-thick $\mathrm{SiO}_{\mathrm{x}} \mathrm{N}_{\mathrm{y}}$ layer modelled by FEM by using the conduction model.

[2] D. Fabiani, G. C Montanari, C. Laurent, G. Teyssedre, P. H. F. Morshuis, R. Bodega, L. A. Dissado and U. H. Nilsson "Polymeric HVDC Cable Design and Space Charge Accumulation" IEEE Electrical Insulation Magazine Vol. 23, pp. 11-18, 2007.

[3] I. Plesa, P.V. Notingher, S. Schlogl, C. Sumereder and M. Muhr "Properties of polymer composites used in High-voltage applications" Polymers Vol. 8, pp.173-236, 2016.

[4] J. Swingler "Characterisation of Electrical and Electronic Systems" Elsevier 2015

[5] J.E. Stern, B.D. Terris, H.J. Mamin and D. Rugar "Exposition and imaging of localized charge on insulator surfaces using force microscope" Appl. Phys. Lett. Vol. 53, pp. 2717-2719, 1998.

[6] C.A. Rezende, R.F. Gouveia, M.A. da Silva and F. Galembeck "Detection of charge distributions in insulator surfaces" J. Phys.: Condens. Matter Vol. 21, pp. 263002-263021, 2009.

[7] M. Ishii "Static states and dynamic behavior of charges: observation and control by scanning probe microscopy" J. Phys.: Cond. Matter Vol. 22, pp. 173001-173013, 2010

[8] K. Makasheva, B. Despax, L. Boudou and G. Teyssedre "Dielectric Layers for RF-MEMS Switches: Design and Study of Appropriate Structures Preventing Electrostatic Charging" IEEE Trans. Dielectrics and Electrical Insulation Vol. 19, pp. 1195-1202, 2012

[9] K. Makasheva, C. Villeneuve-Faure, C. Bonafos, C. Laurent, A. Pugliara, B. Despax, L. Boudou and G. Teyssedre "Dielectric Engineering of Nanostructured Layers to Control the Transport of Injected Charges in Thin Dielectrics" IEEE Transaction on Nanotechnology Vol. 15, pp. 839-848, 2016.

[10] C. Villeneuve-Faure, K. Makasheva, L. Boudou and G Teyssedre "Charge injection in thin dielectric layers by atomic force microscopy: influence of geometry and material work function of the AFM tip on the injection process" Nanotechnology Vol. 27, pp. 245702-245712, 2016.

[11] G.C. Stevens and P.J. Blaird "Nano- and Mesomeasurement methods in the study of dielectric" IEEE Trans. Dielectr. Insul. Vol. 12, pp. 979-992, 2005.

[12] O. G. Reid, K. Munechika, and D. S. Ginger "Space Charge Limited Current Measurements on Conjugated Polymer Films using Conductive Atomic Force Microscopy" Nanoletters Vol. 8, pp. 1602-1609, 2008.

[13] T. G. Ruskell, R. K. Workman, D. Chen, D. Sarid, S. Dahl, and S. Gilbert "High resolution Fowler-Nordheim field emission maps of thin silicon oxide layers" Appl. Phys. Lett. Vol. 68, pp. 1063-1068, 1996.

[14] U. Celano, T. Hantschel, G. Giammaria, R. Chintala, T. Conard, H. Bender and W. Vandervorst "Evaluation of the electrical contact area in contact-mode scanning probe microscopy" J. Appl. Phys. Vol. 117, pp. 214305-214310, 2015.

[15] V. Yanev, T. Erlbacher, M. Rommel, A. J. Bauer and L. Frey "Comparative study between conventionnal macroscopic I-V techniques and advanced AFM based methods for electrical characterization of dielectrics at nanoscale" Microelectronic Engineering Vol. 86, pp. 19111914, 2009. 